\title{
Metáforas de la guerra en textos de divulgación sobre la pandemia*
}

\author{
MIREYA CISNEROS-ESTUPIÑÁN** \\ CLARENA MUÑOZ-DAGUA ${ }^{3 * * *}$
}

Recepción: 22 de julio de 2021

Aprobación: 22 de septiembre de 2021

Forma de citar este artículo: Cisneros-Estupiñán, M. \& Muñoz-Dagua, C. (2021). Metáforas de la guerra en textos de divulgación sobre la pandemia. Cuadernos de Lingüistica Hispánica, (38), e13117

Whttps://doi.org/10.19053/0121053X.n38.2021.13117

* Artículo derivado del proyecto internacional de ALFAL titulado "Difusión del español por los medios" (https:// www.mundoalfal.org/es/content/proyectos), en la línea "Lenguaje y Educación" del Grupo Estudios del Lenguaje y la Educación avalado por El Colegio Mayor de Cundinamarca y la Universidad Tecnológica de Pereira (Colombia).

* Doctora en Ciencias de la Educación de la Universidad del Cauca. Magíster en Lingüística Española. Profesora de la Universidad Tecnológica de Pereira, Colombia. Grupo Estudios del Lenguaje y la Educación, Categoría A1 de Minciencias. mireyace@gmail.com (1) https://orcid.org/0000-0002-5519-7192

*** Doctora en Lingüística de la Universidad de Buenos Aires. Magíster en Lingüística Española. Profesora de la Universidad Colegio Mayor de Cundinamarca, Colombia. Grupo Estudios del Lenguaje y la Educación, Categoría A1 de Minciencias 1 https://orcid.org/0000-0002-5358-9002 


\section{Resumen}

Los textos publicados en medios periodísticos se constituyen en orientadores en un tema de alcance mundial. Este artículo se enfoca en la conceptualización bélica de la COVID-19, con base en analogías fundamentadas en el desorden, la decadencia y la invasión, las cuales en su composición corroboran cómo los conceptos sobre los que se construyen estos textos reflejan una forma de mirar la sociedad, replicarla e instalarla en el cuerpo humano. Nuestra reflexión se fundamenta en metáforas seleccionadas de textos de periodismo científico publicados en internet entre marzo y septiembre del 2020, los cuales reformulan información compleja para acercarla a un público amplio y no especializado. Hacemos énfasis en las posibilidades que ofrecen las representaciones metafóricas para ver un concepto en términos de otro y, al mismo tiempo, llamamos la atención sobre el uso reiterativo de imágenes bélicas en las que priman ideas sobre batallas, armas, defensas y ataques, que evidencian cómo el discurso de la autoridad y el control subyace y se instala en la metáfora que infunde temor.

Palabras clave: pandemia, guerra, metáfora, periodismo científico, virus.

\section{Metaphors of War in Journalistic Media Texts about the Pandemic}

\section{Abstract}

Texts published in journalistic media become guides in a world-wide topic. This paper focuses on the warlike conceptualization of COVID-19, based on analogies founded on disorder, decadence and invasion, which in their composition corroborate how the concepts on which these texts are built reflect a way of looking society, replicate it, and install it in the human body. Our reflection is grounded on selected metaphors from scientific journalism texts published on the internet between March and September 2020, which reformulate complex information to bring it closer to a broad and nonspecialized audience. We emphasize the possibilities offered by metaphorical representations to see one concept in terms of another and, at the same time, we draw attention to the repetitive use of warlike images in which ideas about battles, weapons, defenses, and attacks prevail, showing how the discourse of authority and control underlies and is installed in the metaphor that instills fear.

Keywords: pandemic, war, metaphor, science journalism, virus. 


\section{Métaphores de la guerre dans les textes populaires sur la pandémie}

\section{Résumé}

Des textes publiés dans les médias sont utilisés pour donner des conseils sur un thème de portée mondiale. Cet article se concentre sur la conceptualisation guerrière de COVID-19, basée sur des analogies fondées sur le désordre, la décadence et l'invasion, qui, dans leur composition, corroborent la manière dont les concepts sur lesquels ces textes sont construits reflètent une façon de voir la société, de la reproduire et de l'installer dans le corps humain. Notre réflexion s'appuie sur des métaphores sélectionnées à partir de textes de journalisme scientifique publiés sur internet entre mars et septembre 2020, qui reformulent de l'information complexe pour la rapprocher d'un large public de non-spécialistes. Nous soulignons les possibilités offertes par les représentations métaphoriques de voir un concept en termes d'un autre et, en même temps, nous attirons l'attention sur l'utilisation répétée des images de guerre dans lesquelles les idées de batailles, d'armes, des défenses et d'attaques qui mettent en évidence comment le discours de l'autorité et du contrôle sous-tend et est installé dans la métaphore qui instille la peur.

Mots clés: pandémie, guerre, métaphore, journalisme scientifique, virus.

\section{Metáfores de guerra em textos de divulgação sobre a pandêmica}

\section{Resumo}

Os textos publicados na mídia jornalística constituem guias em um tema mundial. Este artigo enfoca a conceituação bélica do COVID-19, a partir de analogias baseadas na desordem, decadência e invasão, que em sua composição corroboram como os conceitos sobre os quais esses textos são construídos refletem um modo de olhar a sociedade, replicá-la e instalá-la em o corpo humano. Nossa reflexão se baseia em metáforas selecionadas de textos de jornalismo científico publicados na internet entre março e setembro de 2020, que reformulam informações complexas para aproximá-las de um público amplo e não especializado. Enfatizamos as possibilidades oferecidas pelas representações metafóricas de ver um conceito em termos de outro e, ao mesmo tempo, chamamos a atenção para o uso repetitivo de imagens bélicas em que prevalecem ideias sobre batalhas, armas, defesas e ataques, evidenciando como o discurso de autoridade e controle está subjacente e se estabelece na metáfora que instila 0 medo.

Palavras-chave: pandemia, guerra, metáfora, jornalismo científico, vírus. 


\section{Introducción}

La metáfora es un mecanismo estratégico cuando se trata de comunicar contenidos complejos y abstractos a una audiencia masiva, heterogénea y no necesariamente iniciada en la temática expuesta. Importantes estudios, entre ellos los de Lakoff y Johnson (1986) y Lakoff (2007), han demostrado que este es un fenómeno que va más allá de las palabras, pues, como producto de la interacción social, la esencia de la metáfora consiste en que permite entender un dominio de la experiencia en términos de otro.

En el caso de la pandemia que por casi ya dos años ha afectado a la mayor parte de la población mundial, con graves consecuencias sanitarias, económicas y sociales, las metáforas han sido recurrentes como mecanismo para acercar el conocimiento especializado a la población sumida en el temor por el contagio. Muchos son los campos semánticos que se han abarcado para explicar los efectos del virus en el cuerpo, tales como "tormentas", "cascadas", "tsunamis" o "viajes". Asimismo, se utilizan las "fichas de dominó que se caen" para explicar la necesidad de mantener la distancia física entre personas, o "cerillas que se queman" para aludir a la urgencia de quedarse en casa a fin de frenar la expansión, o la alusión "al fuego que no se termina de extinguir", con el fin de señalar aspectos particulares de la gestión de la pandemia, como la necesidad de una actuación rápida frente a los contagios, las distintas fases de evolución y el trabajo esencial de los trabajadores de la salud.

Sin embargo, en medio de la avalancha de metáforas, las más sobresalientes para referirse a la pandemia a través de los medios de difusión, son las relacionadas con la guerra. Así, al analizar las analogías que subyacen en estas metáforas -fundamentadas en el desorden, la decadencia y la invasión- es posible entrever cómo los conceptos sobre los que se construyen estos textos reflejan en su enfoque retórico una forma de mirar la sociedad y replicarla e instalarla en el cuerpo humano. En este sentido, la importancia de la metáfora como mecanismo cognitivo y comunicativo no se reduce solo a la posibilidad de comprender y explicar la realidad, sino que la elección de una u otra permite interpretar la realidad de distinta manera.

Con base en estos elementos, el artículo presenta el resultado de una exploración de las metáforas empleadas en textos de periodismo científico publicados en internet entre marzo y septiembre del 2020, que informan acerca de la pandemia a un público no especializado. El interés se centra en determinar cómo la conceptualización bélica de la enfermedad, sustentada en las analogías del desorden, la decadencia y la invasión, se instala en el cuerpo humano y se extiende a la sociedad.

\section{Fundamentación teórica}

El nombre metáfora viene del latín metaphŏra, y este, del griego $\mu \varepsilon \tau \alpha \varphi о \rho \alpha ́$, que significa literalmente traslación o transferencia; ella implica la asociación de dos o más ideas en la mente del emisor, en correspondencia con los rasgos comunes que establecen el puente entre los 
conceptos que están en juego. La comprensión de la metáfora como una comparación y sustitución entre dos entidades se remonta a los tiempos de Aristóteles (2002, 2006), que la define como una figura retórica que consiste en el empleo de las palabras en sentido distinto del que el sistema léxico les asigna, en virtud de una semejanza.

En el marco de la filosofía de la retórica, Black (1966) desarrolla la teoría de la interacción planteada por Richards (1936), según la cual en la construcción de la metáfora se ponen en interacción dos conceptos, cuya eficacia consiste en que, mediante una operación intelectual, se haga ver un objeto primario trasformado formalmente por un concepto secundario como si pasara por el filtro de este. Al evocar tópicos comunes de los dos objetos, es posible ver un objeto más abstracto mediante la referencia a otro más concreto y cercano. La metáfora, de ese modo, crea semejanza y aporta información; por tanto, enseña y no se limita a ser un simple ornamento del discurso.

Desde la lingüística cognitiva, Lakoff y Johnson (1986) destacan el papel de la metáfora como mecanismo cognitivo mediante el cual comprendemos conceptos de un dominio de la experiencia con apoyo en conceptos de otro dominio, generalmente más familiar y concreto. Para estos autores, las metáforas tienen repercusiones en la vida misma, pues condicionan la forma de entender el mundo y la manera de actuar en él. En la base del conjunto de expresiones metafóricas que vinculan dos dominios lejanos, se ubica la llamada metáfora conceptual. De este modo, los mecanismos de creación metafórica no son estrictamente lingüísticos, sino más bien conceptuales. La metáfora dota de soporte material físico y analizable a una idea y ayuda a traducir el mundo a palabras. En este sentido, la conceptualización del cuerpo, la salud, la enfermedad tiene una base cultural, pues las metáforas sobre las cuales se cimientan los conceptos relacionados con ellos reflejan valores sociales y culturales.

Por su parte, Andrew Goatly sostiene en Languaje of Methafors (1997) que la metáfora se produce cuando una unidad del discurso es utilizada para referirse de manera no convencional a un concepto, a partir de una semejanza. De acuerdo con el autor, las metáforas son relevantes porque tienen propósitos que se definen en la actividad humana social y, en consecuencia, sirven a una pluralidad de funciones en diferentes registros, tales como llenar vacíos léxicos; explicar conceptos abstractos en términos más familiares para los destinatarios; argumentar mediante analogía; realizar llamados a la acción, por ejemplo, en las "avalanchas" de respaldo a la actividad sanitaria; encubrir, disfrazar o exagerar con eufemismos la realidad, como "se fue de viaje" para hablar de la muerte, o sostener una ideología, cuando, por ejemplo, la inmigración se asimila a una "invasión" a la cual debe hacerse frente.

Para Langacker (2015), la conceptualización sería una habilidad que permite construir cognitivamente una misma situación de distintas maneras, es decir, 
que se producen conceptualizaciones alternativas que dependen de parámetros 0 maneras de elegir lo que se quiere ver y que hacen que desde allí se preste mayor o menor atención. De allí que la metáfora conceptual sea una de esas alternativas en las que, como lo considera Kövecses (2015, pp. 1-15), el contexto juega un papel fundamental en la construcción y producción de las metáforas con sus respectivos significados. En ese sentido, al estar el mundo en un contexto bélico mostrado con mayor énfasis en los medios de comunicación de masas, la mejor explicación conceptual de la pandemia involucra las metáforas bélicas. En Kövecses (2010, 2015, 2021) encontramos que la metáfora conceptual está constituida por un conjunto de "mapeos" o de correspondencias sistemáticas entre dos dominios de la experiencia, que se representan como marcos mentales o modelos cognitivos, cuyo significado se basa en tales correspondencias. En el caso que nos ocupa, estos dos dominios son la guerra y la enfermedad.

En los estudios de Muñoz-Dagua $(2014,2018)$ sobre la metáfora en textos de divulgación científica, se considera que los usos metafóricos son herramientas eficaces para explicar conceptos que pueden resultar abstractos para el no experto; sin embargo, el uso reiterado puede hacer que la priorización de unas características sobre otras condicionen al lector a "aceptar como verdadero un concepto y ello trae implicaciones sobre la visión del mundo que se trasmite a partir de dicha elección" (Muñoz-Dagua, 2018, p. 122).

\section{Corpus y método}

Aquí se realiza un análisis cualitativo y contrastivo de los usos de la metáfora bélica en 11 metáforas tomadas de textos de periodismo científico publicados en internet entre marzo y septiembre del 2020. Los criterios para la definición del corpus fueron: 1) consolidar un grupo de escritos de periodismo científico que dieran razón del manejo del español en los medios de difusión masiva; 2) seleccionar en estos textos de divulgación al menos tres tipos de formatos -artículo, entrevista, nota de opinión; 3) enfatizar en el uso de metáforas bélicas como recurso para describir, exponer o referirse a la pandemia; 4) verificar que los autores responsables de reformular información compleja a un público amplio fueran periodistas, médicos o analistas de diferentes profesiones.

En el análisis se tienen en cuenta los planteamientos de Díaz-Rojo (2005) en cuanto a la caracterización de la terminología médica. De acuerdo con el autor, el léxico científico y médico surge en contextos culturales específicos y está imbricado con los modelos culturales procedentes de otros campos de la cultura y ámbitos del conocimiento. De este modo, las áreas conceptuales más comunes en la medicina que se emplean como fuente metafórica para conceptualizar y denominar sus nociones son la sociedad, la naturaleza, las cosas físicas creadas por el ser humano y el mundo de la comunicación y la información. En este contexto, en el orden social se encuentra la conceptualización bélica de la enfermedad, en la cual se reconocen tres 
analogías: "a) como desorden, b) como decadencia, y c) como invasión” (Díaz-Rojo, 2005, p.40).

\section{Análisis}

En la actualidad, múltiples escritos llegan al público a través de las redes, con orientaciones, definiciones y explicaciones, avances inusitados y predicciones alarmantes acerca del problema sanitario que aqueja al mundo. Debido a las medidas adoptadas para la prevención y protección del contagio con la enfermedad del coronavirus causada por el SARS-CoV-2, toda esta información llega en gran medida a través de internet. De tal manera que se posibilita un acceso a diario, en la cotidianidad del hogar, a textos periodísticos de ciencia que, como instancia de divulgación orientada a un público amplio, presentan una diversidad de formatos: crónica, artículo, entrevista, nota de opinión o columna.

Así, los textos periodísticos sobre ciencia involucran una tarea propia de la divulgación que consiste en reformular información compleja para que sea comprendida por una audiencia amplia y heterogénea, no iniciada en la temática expuesta. Estos procesos de reformulación comprenden acciones lingüísticas como cambios en la sintaxis y en los formatos de los textos que operan como fuente, la incorporación de información adicional, además del uso de procedimientos adecuados para la definición y explicación de términos técnicos. En este último aspecto, es decir, en la actividad de transformar un conocimiento especializado a un saber más accesible para un público no especialista, la metáfora se constituye en un mecanismo esencial para lograr, tal como señala Fuller (1998, p. 35), que "el saber producido por una comunidad restringida de expertos, llegue a grupos amplios de población".

Al examinar en los textos de divulgación cómo se conceptualiza la COVID$19^{1}$, enfermedad causada por el nuevo coronavirus conocido como SARS-CoV-2, la cantidad de imágenes referidas a la guerra es abundante y elocuente. En este marco, con las analogías del desorden, la decadencia y la invasión es posible acceder a campos semánticos que se asocian a una serie de ítems léxicos, los cuales, en su reiteración, apuntan a poner de relieve la "lucha armada" prolongada que se libra a través de "diversas batallas" para erradicar "el agente" que se ha "infiltrado" en el cuerpo.

Desde otra perspectiva, Sabucedo et al. (2020) reconocen que la metáfora bélica está presente en la interpretación de la pandemia de la COVID-19 y consideran que "su utilización resulta problemática porque si bien evoca imágenes, como resistencia o heroísmo, de connotaciones positivas, también remite a otras, como enfrentamiento, obediencia o enemigo, que denotan conflicto" (2020, p. 619); por lo cual los autores sugieren en su conclusión que "la metáfora de la guerra debe ser

1 La Organización Mundial de la Salud tuvo noticia por primera vez de la existencia de este nuevo virus el 31 de diciembre de 2019, al ser informada de un grupo de casos de "neumonía vírica" que se habían declarado en Wuhan (República Popular China). (OMS, 2021). 
sustituida por otra que tenga como elemento cognitivo y emocional central el cuidado por el otro y la cooperación" (2020, p. 623)

\section{La pandemia como desorden}

En este primer tipo de metáforas, la enfermedad se asume como una revolución política, en la que el trastorno patológico, cambio o alteración en el funcionamiento del organismo se concibe como una rebelión bélica contra el orden establecido -el estado de salud- que origina un conflicto o una guerra. La terapia, por su parte, actuará como mecanismo de defensa contra los agentes causantes de la enfermedad. El léxico del control, las órdenes, la regulación de funciones y los ataques de una u otra parte para contrarrestar al "enemigo público número 1", hacen parte de esta conceptualización, como sucede en [1].

[1] Sin embargo, el origen detrás de este gran caos internacional tiene lugar en el mundo de lo invisible al ojo humano, donde solo los microscopios de mayor potencia y diversas técnicas de laboratorio nos permiten ver o detectar al enemigo público número 1: el virus SARS-CoV-2. ¿Cómo este diminuto agente infeccioso, de apenas 125 nanómetros de diámetro y en el limbo entre la vida y la muerte, ha sido capaz de provocar tal gigantesco efecto sobre el mundo? Así actúa el virus para atacar a las personas: Todo comienza en el interior del cuerpo humano [...] Es allí, principalmente en las células de la mucosa de las vías respiratorias superiores, donde el virus tiene la oportunidad de introducirse como si fuera un caballo de Troya. La infiltración microscópica ocurre gracias a que este virus ha desarrollado "llaves" específicas (proteínas) que le sirven para abrir las "cerraduras" de estas células humanas y tener vía libre para infiltrarse en ellas. (Samper, 2020)

Como corresponde al enemigo, el virus, un "diminuto agente infeccioso", "ataca" el cuerpo y como si fuera un "caballo de Troya", aquel artilugio estratégicomilitar, con soldados ocultos en su interior, aprovechado por los aqueos para introducirse en la fortificación de Troya, despliega todo su arsenal: saca "las llaves" para abrir cerraduras e "infiltrarse" en las células humanas.

En [2], la analogía explícita permite visualizar quiénes son los protagonistas de la guerra y cuáles son sus responsabilidades y funciones en el "campo de batalla".

[2] Quizás esto suene dramático, pero el coronavirus es como una guerra. Los soldados son trabajadores de la salud. El enemigo es el virus. El campo de batalla son los hospitales. Estamos descubriendo que la vida se puede convertir en una moneda de diez centavos. (Shannon, 2020)

De igual modo, en [3] se presenta a la humanidad en un escenario de guerra contra el "enemigo invisible" pero "poderoso". La guerra en el cuerpo es la guerra de todos los países aliados por un fin común:

[3] La humanidad está en guerra, los líderes de los Estados lo siguen reiterando. Contra un enemigo invisible pero poderoso, de solo diez milésimas 
de milímetro de tamaño. Pero, aunque el coronavirus ha cambiado el estilo de vida de miles de millones de personas, imponiendo restricciones sin precedentes a la libertad de movimiento y a la vida económica y pública, el COVID-19 no ha logrado anular los antagonismos políticos existentes en el mundo. (DW, 2020)

En [4] se hace referencia a la contraofensiva que desarrollan los médicos para afrontar la "guerra sanitaria". Esta imagen es recurrente en las redes sociales y en los medios informativos, en los cuales se aplaude masivamente la labor de médicos y, en general, de los trabajadores de la salud que afrontan la pandemia. A medida que el virus se propaga en todos los países, se hace desde el confinamiento una valoración al trabajo incansable del personal sanitario.

[4] En esta pandemia, los médicos se han convertido en los héroes del mundo. Hoy son la primera línea de batalla de lo que el presidente francés Emmanuel Macron describió como una "guerra sanitaria" con un enemigo "invisible y escurridizo". (Semana.com, 2020)

Así mismo, con una afirmación tajante en [5] se acentúa el perfil del enemigo público que provoca la guerra:

[5] El COVID-19 es nuestro enemigo común. Debemos declarar la guerra contra este virus. (Guterres, 2020) ${ }^{2}$

Así, la conceptualización de la pandemia como desorden quizás ayuda a entender la gravedad de la situación que vive el mundo: imágenes de pasillos de hospitales colapsados con pacientes gravemente enfermos, personal de la salud que trabaja sin tregua, miles de muertos, todos ellos caídos frente a un enemigo que ataca sin parar, llamados estratégicos a utilizar "armas" para prevenir el contagio.

\section{La pandemia como decadencia}

En este segundo grupo de representaciones metafóricas, la pandemia se percibe como una degradación social, de tal manera que se asocia a "una plaga", "una peste", "una mutación", "un detonante", que requiere máxima atención por los peligros que conlleva, como sucede en [6] donde con el calificativo "famoso" se asimila al virus a una "mutación" con efectos nocivos sobre el hombre, es "maligno", pues es producido en serie, fabricado.

[6] ¿Es acaso el coronavirus el detonante para la Tercera Guerra Mundial? Todo indica que sí. A medida que pasan los días y aumentan las cifras, cada vez somos más los que creemos que el famoso virus es una mutación maligna; 0 mejor, un virus fabricado y manipulado por el hombre. (Rojas, 2020)

2 António Guterres, noveno secretario general de las Naciones Unidas desde 2017. Fue alto comisionado de las Naciones Unidas para los Refugiados de 2005 a 2015, trabajó durante más de 20 años en la administración pública y fue primer ministro de Portugal entre 1995 y 2002. 
Por su parte, en [7], el virus se nombra, con cierto desdén, como una "cosa minúscula" que contaminó a un paciente y luego provocó la mayor "parálisis global" en la historia de la humanidad:

[7] Una cosa minúscula que contaminó un primer paciente en China a finales de 2019 provocó la mayor parálisis mundial jamás constatada en la historia de la humanidad. Hay una desproporción entre el tamaño y el campo de acción del virus, que trabaja a escalas infinitesimales, y el pánico y la parálisis globales que se apoderaron del mundo. (AFP, 2020)

En [8], "la peste", "el contagio" aparecen como un "dispositivo biopolítico global" que con su poder y su presencia prolongada amenaza a la humanidad:

[8] El miedo hace funcionar de manera espléndida los dispositivos disciplinarios. El miedo a la peste, al contagio, hace que las personas desesperadas, en procura de su propia supervivencia se entreguen sin resistencia alguna a los controles y a la vigilancia. La docilidad aumenta en la medida que las evidencias médicas y científicas ratifican el peligro. [...] Se ha logrado la unidad en contra de un enemigo común, omnipresente e invisible que nos amenaza a todos. El coronavirus se ha convertido en el máximo dispositivo biopolítico global. (Ávila, 2020)

De este modo, el virus pandémico, como la guerra, degrada, disminuye, controla el cuerpo y la sociedad atemorizada que ha sentido el impacto y efectos devastadores de su "invasión" en todas las áreas, como aparece en algún titular de un periódico: "el coronavirus es democrático pero sus consecuencias, no". (DW.com, 2021)

\section{La pandemia como invasión}

En este caso, la enfermedad es una invasión militar de seres extraños en el organismo, como sucede con las infecciones, es decir, la irrupción violenta de microorganismos en el cuerpo, con fines estratégicos o únicamente tácticos. En [8] se explica qué ocurre cuando el virus "ataca" el cuerpo, "entra en las células" y se "adueña" de las maquinarias celulares. En su conquista del cuerpo humano, "obliga a las células a trabajar para él" y a "fabricar" millones de copias del virus, "destruir" células y, cual agente que ejerce sus funciones de forma encubierta, "expandirse", "multiplicarse" y poner en peligro el organismo entero sin que haya señales de alarma. Los periodos de infección e incubación se nominan como la "calma antes de la tormenta".

[9] Una vez que el coronavirus ha logrado entrar en las células, este se adueña de las maquinarias celulares para usarlas en su propio beneficio. Obliga a las propias células del cuerpo humano a fabricar millones y millones de copias del virus mediante la síntesis de su ARN (su material genético) y sus proteínas que se ensamblan para crear nuevos virus. Estos nuevos virus salen de las células, destruyéndolas, y se dirigen a las células vecinas para repetir el ciclo indefinidamente. El virus SARS-CoV-2 es capaz de expandirse y multiplicarse 
en las células del aparato respiratorio (también en otros tipos de células en menor medida, como las células intestinales), sin que nuestro cuerpo mande señales de alarma durante varios días. Es lo que llamamos el periodo de incubación, el tiempo que pasa desde que se produce el contagio hasta que se desarrollan los síntomas; la calma antes de la tormenta. (Samper, 2020)

En [10], la acción de "invadir" se desarrolla paso a paso con la metáfora que está en juego en el discurso. Poco a poco, se explica cómo se utilizan tácticas y estrategias para infectar el cuerpo. Así, se expone que la COVID-19 se "vale", usa una proteína para abrir "la puerta" y también "las compuertas celulares" para adentrarse, penetrar el organismo, invadirlo e infectarlo.

[10] Los científicos ya sabían que el Covid-19 se valía de una proteína llamada 'ACE2' para abrir la puerta que le permitiese entrar en las células humanas. Ahora ya se sabe cómo lo hacen: a través de una proteína vírica que encaja en la ACE2 como una llave en una cerradura. Esta es la conclusión a la que llegó un equipo de científicos del Instituto de Estudios Avanzados Westlake, en Hangzhou, y la Universidad Tsinghua de Pekín. El descubrimiento, publicado en el mes de marzo en la revista Science, sea adentra en la estructura celular para estudiar los entresijos de la proteína humana, y descubrir cómo el virus la utiliza para penetrar en nuestro organismo. La unión de una proteína vírica y la ACE2 abre las compuertas celulares para que el coronavirus pueda penetrar y duplicarse en su interior. La maquinaria celular humana utiliza el ARN vírico como propio, por lo que fabrica proteínas virales como si de humanas se tratasen. A partir de ahí, el material genético vírico -y los mismos virus- se van multiplicando hasta acabar con las membranas de la célula en cuestión y disponerse a infectar otras células cercanas. (Navas, 2020)

Finalmente, en [11], la conceptualización bélica de la enfermedad se despliega con la presentación de una pregunta retórica que permite detallar en la respuesta como se desarrolla el proceso de invasión en el organismo y como esta acción sobre el cuerpo puede llegar a ser perversa, maligna, "siniestra", a partir de los "tentáculos" que coadyuvan a la rápida propagación de la infección:

[11] Desde el inicio de la pandemia de covid-19 una pregunta que ha obsesionado a varios científicos alrededor del mundo es: icómo este coronavirus invade y reprograma a las células humanas para provocar la infección y causar la muerte? Conocer la respuesta es crucial en la búsqueda de medicamentos capaces de frenar al virus antes de que lleve a cabo esos procesos. Un equipo internacional de científicos que ha estado explorando esta interacción descubrió varias claves de cómo el Sars-Cov-2 infecta las células. El hallazgo más sorprendente -que lograron comprobar con extraordinarias imágenes- es que las células humanas infectadas por el coronavirus sufren una "siniestra" transformación. Las células, siguiendo las instrucciones del virus, desarrollan largos filamentos, similares a tentáculos, que, se cree, podrían ayudar a la rápida propagación por el organismo. "Lo que descubrimos es que el virus induce a la célula a crear estas protuberancias, que son como largas ramas o tentáculos", "En otros virus se ha visto que 
(estas protuberancias) desempeñan un papel en la rápida propagación de la infección porque le ayudan al virus a invadir células cercanas", agrega el investigador. (Nathional Geographic, España, 2020)

A propósito de la metáfora como invasión, Sontag (2017) se refiere en su ensayo sobre las metáforas militares utilizadas para describir la enfermedad más temida en el siglo XX, llamada SIDA, las cuales comunican contenidos culturales e ideológicos y llevan implícita la represión y la violencia de Estado. Según la autora mencionada, la metáfora militar apareció en medicina hacia 1880, cuando se identificaron las bacterias como agentes patógenos capaces de invadir el cuerpo e infiltrarse en él. En adelante, se ha seguido utilizando estas metáforas cuya "descripción no se limita a la evolución clínica de la enfermedad y su tratamiento, sino que la enfermedad se convierte en el enemigo con el que la sociedad entera debe alzarse en pie de guerra." (Sontag, 2017, pp. 79-80)

\section{Conclusiones}

Durante esta pandemia, como seguramente no había ocurrido antes, miles de personas se han acercado al conocimiento de la enfermedad a través de la metáfora bélica. A partir de los textos estudiados puede decirse que las expresiones lingüísticometafóricas derivadas del ámbito militar y de la guerra evidencian una manera de razonar y de pensar que conceptualiza el cuerpo afectado por el coronavirus de una forma antagonista y hostil, atacado por enemigos que se apoderan de él y le hacen daño. Además, esta metáfora tiene el efecto de normalizar el que se conciba la enfermedad como una invasión de enemigos contra los que hay que defenderse. El paciente ha de constituirse en una especie de soldado y combatir en contra de su propio cuerpo, así como en contra de los enemigos externos. El cuerpo desencadenará operaciones militares y movilizará defensas, mientras que los médicos realizarán intervenciones agresivas.

Así, las metáforas bélicas utilizadas para informar sobre el coronavirus activan marcos semánticos que, en principio, no parecieran ser muy diferentes a las que se escuchan en las trasmisiones deportivas: "se defiende el título", "se ataca al oponente" o, en otros contextos, también se "lucha contra la desigualdad", se trata de "vencer los obstáculos" o "conquistar el amor". Sin embargo, tal como se ha analizado, la continuidad, la reiteración y las analogías fundamentadas en el desorden, la decadencia y la invasión han logrado, en la práctica, que el lenguaje de la guerra se trivialice, con toda la ideología subyacente, se instale en el cuerpo y llegue con todo su vocabulario cada vez a un mayor número de personas, de tal manera que los límites se pierden: no solo está en guerra el cuerpo del enfermo o el equipo médico, sino toda la sociedad.

De hecho, hoy quienes se ocupan del análisis de la pandemia acuden a la metáfora bélica para pensar en que se necesita luchar juntos contra el virus. En algunos países se mantiene esta retórica de la guerra y, dada la coyuntura 
de extensión espacial e impacto social, político y económico de la pandemia, se extiende el léxico del control y la lucha contra el enemigo a la necesidad de contar con el estamento militar y el comando de crisis. Así, con las imágenes de la guerra, en plena pandemia, la metáfora bélica en algunas ocasiones puede coadyuvar a fundamentar políticas que tienen efectos sobre el bienestar de la población.

Es aquí donde habría que hacer una lectura crítica y preguntar: ¿con los conceptos que vehicula la metáfora bélica, se alimentan prejuicios y actitudes de control social? ¿la metáfora de la guerra es parte de una estrategia para justificar lo que hacen algunos estamentos? No podemos olvidar que con el potencial movilizador que subyace en el vocabulario del combate, el enemigo, la batalla, el ataque, la lucha, las armas, la defensa y la estrategia, los propósitos de gobernantes, trabajadores de la salud, médicos, enfermos, organismos militares pueden aparecer estrechamente ligados, aun cuando no estén valorando 0 mirando la misma realidad.

En todo caso, este trabajo solo intenta ser una aproximación al tema. Será necesario realizar un estudio posterior con un corpus más amplio, que incluya otros campos semánticos utilizados para describir la enfermedad con el fin de determinar cómo ha sido la evolución de este tipo de metáforas durante el tiempo de pandemia.

\section{Referencias}

AFP (2020, 5 de mayo). El coronavirus, un agente de la globalización minúsculo pero superpotente. France 24. https://www.france24.com/es/20200505-elcoronavirus-un-agente-de-la-globalización-minúsculo-pero-superpotente

Aristóteles. (2002). Retórica (A. Bernabé, trad.) (4. ${ }^{\mathrm{a}}$ reimp.). Alianza.

Aristóteles. (2006). Poética (E. Sinnot, trad.). Colihue.

Ávila, k. (4-05-2020). El coronavirus como dispositivo. Efecto Cocuyo. https://www. opendemocracy.net/es/el-coronavirus-como-dispositivo/.

Black, M. (1966). Models and Metaphors. Cornell University.

Díaz-Rojo, J. A. (2005). Terminología médica, cultura e ideología. Quaderns de Filologia. Estudis Lingüistics, 10, 31-51. https://ojs.uv.es/index.php/ qfilologia/article/view/5079

DW.com (2020, 30 mar.). Coronavirus: nuevo frente en guerra por la información entre las potencias EE.UU., Rusia y China. DW. https://www.dw.com/es/ coronavirus-nuevo-frente-en-guerra-por-la-información-entre-las-potenciasee-uu-rusia-y-china/a-52962487. 
DW.com (2021, 26 ene.). El coronavirus es democrático, pero sus consecuencias, no. DW. https://www.dw.com/es/el-coronavirus-es-democrático-pero-lasconsecuencias-no/a-56348620.

Fuller, G. (1998). Cultivating Science. Negotiating Discourse in the Popular Texts of Stephen Jay Gould. In J. R. Martin \& R. Veel (Eds.), Reading Science. Critical and Functional Perspectives on Discourses of Science (pp. 35-63). Routledge.

Goatly, A. (1997). Languaje of Methafors. Routledge.

Guterres, A. (2020, 30 abr.). COVID-19: Lo superaremos juntos. https://www.un.org/ es/coronavirus/articles/guterres-covid-19-expone-desigualdad-genero.

Kövecses, Z. (2010). A New Look at Metaphorical Creativity in Cognitive Linguistics. Cognitive Linguistics, 21(4), 663-697.

Kövecses, Z. (2015). Where Metaphors Come From: Reconsidering Context in Metaphor. Oxford University Press.

Kövecses, Z. (2021). Standard and Extended Conceptual Metaphor Theory. In X. Wen \& J. Taylor (Eds.), The Routledge Handbook in Cognitive Linguistics (pp. 191-203). Routledge.

Lakoff, G. (2007).Nopienses en un elefante. Lenguajey debatepolitico. Complutense.

Lakoff, G. \& Johnson, M. (1986). Metáforas de la vida cotidiana. Cátedra.

Langacker, R. (2015). Construal. In E. Dąbrowska \& D. Divjak (eds.), Handbook of Cognitive Linguistics (pp. 120-142). De Gruyter Mouton.

Muñoz-Dagua, C. (2014). Metáfora interpersonal léxico-gramatical en la divulgación científica. Universidad Colegio Mayor de Cundinamarca.

Muñoz-Dagua, C. (2018). La economía es un castillo de naipes. Arabismos en metáforas económicas. Revista del Hispanismo. Egipto Candil, 18(1), 104126. https://dialnet.unirioja.es/ejemplar/530327

Nathional Geographic, España. (2020, 5 de mayo). Descubren cómo penetra el coronavirus en las células bumanas. https://www.nationalgeographic.com. es/ciencia/ descubren-como-penetra-coronavirus-celulas-humanas_15274.

Navas, C. (3-07-2020). Consecuencias del coronavirus; la "siniestra" transformación que el Sars Cov2 provoca en las células humanas infectadas. $B B C$, News, Mundo. https://www.bbc.com/mundo/noticias-53265913.

Organización Mundial de la Salud -OMS-. (2021). Brote de enfermedad por coronavirus (COVID-19). https://www.who.int/es/emergencies/diseases/ novel-coronavirus2019?gclid $=$ CjwKCAjw49qKBhAoEiwAHQVToxTqyDzlZHdar yPzOKTUZLMuaC_fBhv7PDRgdPvBkfzXVitcjX1PDhoCybUQAvD_BwE 
Rojas, A. (2020, 20 abr.). COVID-19: La tercera guerra mundial. Pulzo.com https://www. pulzo.com/opinion/el-coronavirus-es-tercera-guerra-mundial-PP883950.

Sabucedo, J., Alzate, M., \& Hur, D. (2020). COVID-19 and the Metaphor of War. International Journal of Social Psychology, 3(35), 618-624.

Samper, E. (2020, 22 mar.). Esto es lo que pasa cuando el coronavirus ataca tu cuerpo. El Diario. https:/www.eldiario.es/sociedad/ataca-coronavirus-SARSCoV-2-cuerpo-humano_0_1008599325.html.

Semana.com. (2020, 22 de mar.). Los gladiadores contra el coronavirus. Especiales Semana. https://especiales.semana.com/heroes-contra-el-coronavirus-encolombia-medicos-enfermeras-personal-sanitario/index.html

Shannon, S. (29 de marzo 2020). La pandemia de coronavirus es realmente como una guerra. KevinMD. https://www.kevinmd.com/blog/2020/03/the-coronaviruspandemic-is-truly-like-a-war.html

Sontag, S. (2017). La enfermedady sus metáforas. El sida y sus metáforas. Penguin Random House. 